\title{
New Platforms For Drug Screening And Toxicology: Necessity Or Need?
}

\author{
Zahra Heydari, Massoud Vosough*
}

- Department of Stem Cells and Developmental Biology, Cell Science Research Center, Royan Institute for Stem Cell Biology and Technology, ACECR, Tehran, Iran

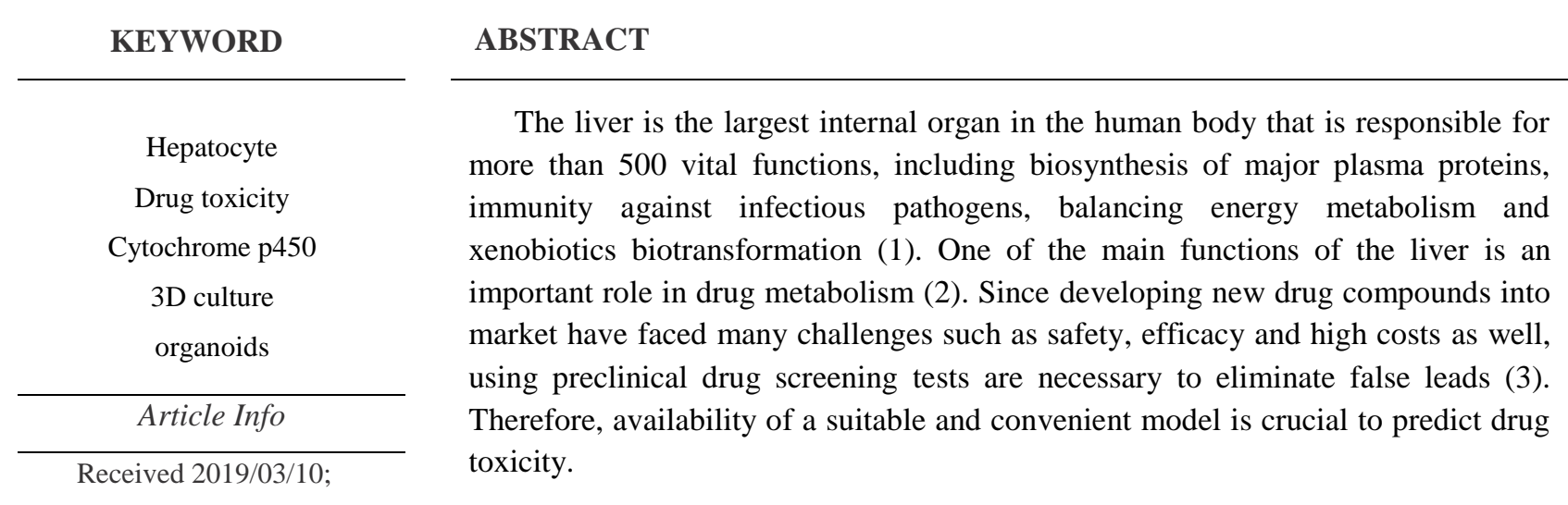

Accepted 2019/03/20;

Published Online 2019

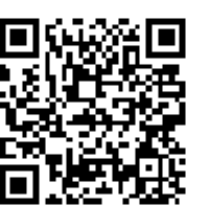

Corresponding Information: Massoud Vosough MD, Ph.D., Royan Institute, Banihashem Sq., Banihashem St., Resalat Highway, P.O. Box 16635-148, Tehran, Iran. Postal Code: 1665659911, Tel: +98 21 22306485, Fax: +98 21 23562507, Email: masvos@ royaninstitute.org

Copyright $\odot$ 2019. This is an open-access article distributed under the terms of the Creative Commons Attribution-noncommercial 4.0 International License which permits copy and redistribute the material just in noncommercial usages, provided the original work is properly cited.

\section{Introduction}

The liver is the largest internal organ in the human body that is responsible for more than 500 vital functions, including biosynthesis of major plasma proteins, immunity against infectious pathogens, balancing energy metabolism and xenobiotics biotransformation (1). One of the main functions of the liver is an important role in drug metabolism (2). Since developing new drug compounds into market have faced many challenges such as safety, efficacy and high costs as well, using preclinical drug screening tests are necessary to eliminate false leads (3). Therefore, availability of a suitable and convenient model is crucial to predict drug toxicity. Although using animal models is helpful in many cases, but due to ethical controversies, high costs, and inter-species and inter-individual diversities, many researchers have tried to find the alternative platforms.
Moreover, high polymorphism in activity of cytochrome p450 enzymes (CYPs) and the enzyme activity are even highly different between two individuals in one species that have caused the use of animal models is not accurate platform for drug screening and toxicity tests (4). Since decades ago, in vitro models have been used, however the most important challenge regarding the use of in vitro human hepatic models is the identification of suitable liver cell sources. In fact, applying the cell sources in different researches depends on aim and study design. Hepatocytes are the main parenchymal cells in liver that play indispensable role in hepatic functions. These cells can be derived from direct differentiation of stem cells e.g. induced pluripotent stem cells (iPSCs) and embryonic stem cells (ESCs). In addition, some hepatocytes cell lines can be used in studies about 
liver. However, these sources are not perfect, iPSCs-derived hepatocytes lack sufficient maturity, therefore they were not able to display CYPs activity properly (5). Moreover, cell lines express alpha-fetoprotein (AFP), which is a fetal marker as well as less activity of CYPs (6). Since fresh ex vivo primary human hepatocytes (PHHs) demonstrates CYPs expression and activity similar to in vivo. They are gold standard platform for drug screening and toxicity assays. The significant challenge in drug development industry is connection between in vitro and in vivo consequences. Therefore, to get this sight, it is a great need to develop a faithful model that can mimic in vivo conditions and microenvironment (7). The studies of maintenance of hepatocytes for long-term or short-time depends on the aim of studies, i.e., incubation of drugs with hepatocytes for couple of hours in PK/PD (Pharmacodynamics/Pharmacokinetics) studies and a few days in toxicology studies. However, long-term preservation of hepatocytes and acceptable functionality of them depend on two factors: the specific cell type used in the study, e.g., primary human hepatocyte and the method of cultivation, e.g., 2D or 3D cultures (8). Liver is made up of different cell types and specific extracellular matrix (ECM) that construct normal liver. Normal physiology and function of hepatocytes strongly depend on cell-cell and cellECM interactions. Although, fundamental studies have been done based on 2D culture, these accomplishments cannot be accountable regarding polarity and function of PHH (9). Nowadays, using 3D cultures including organoids and spheroids can be cited due to similarity with in vivo structure and polarity preservation. Therefore, 3D culture systems have been introduced in order to long-term maintenance of liver-specific functions, increases in sensitivity for drug metabolism and prolonged expression of phase I and II enzymes (10, 11).

In conclusion, in vitro 3D culture models are commonly used to mimic liver functions. They can be applied in toxicology studies. In fact, the toxicity of drugs can be detected after several weeks. Therefore the effect of drugs should be tracked in vitro during long-term and these structures must be simulated in vivo conditions. Primary human hepatocytes that cause high CYPs activity are the best choice to achieve this approach. On the other hand, 3D systems in addition to the use of stromal cells and ECM can be the best method to enhance and maintain functionality in PHH. Nowadays, the increasing need for new drugs has made the use of organoid platforms for drug development as an absolute necessity for pharmaceutical industries.

\section{References}

1. Gissen P, Arias IM. Structural and functional hepatocyte polarity and liver disease. Journal of hepatology. 2015 Oct 31; 63(4):1023-37.

2. Levy G, Bomze D, Heinz S, Ramachandran SD, Noerenberg A, Cohen M, Shibolet O, Sklan E, Braspenning J, Nahmias Y. Long-term culture and expansion of primary human hepatocytes. Nature biotechnology. 2015 Dec 1; 33(12):1264-71.

3. Yan S, Wei J, Liu Y, Zhang H, Chen J, Li $\mathrm{X}$. Hepatocyte spheroid culture on fibrous scaffolds with grafted functional ligands as an in vitro model for predicting drug metabolism and hepatotoxicity. Acta biomaterialia. 2015 Dec 31; 28:138-48.

4. Martignoni M, Groothuis GM, de Kanter R. Species differences between mouse, rat, dog, monkey and human CYPmediated drug metabolism, inhibition and induction. Expert opinion on drug metabolism \& toxicology. 2006 Dec 1;2(6):875-94.

5. Szkolnicka D, Farnworth SL, LucendoVillarin B, Storck C, Zhou W, Iredale JP, Flint O, Hay DC. Accurate prediction of drug-induced liver injury using stem cellderived populations. Stem cells translational medicine. $2014 \quad$ Feb 1;3(2):141-8.

6. Guillouzo A, Corlu A, Aninat C, Glaise D, Morel F, Guguen-Guillouzo C. The human hepatoma HepaRG cells: a highly differentiated model for studies of liver metabolism and toxicity of xenobiotics. 
Chemico-biological interactions. 2007 May 20;168(1):66-73.

7. Bell CC, Lauschke VM, Vorrink SU, Palmgren H, Duffin R, Andersson TB, Ingelman-Sundberg M. Transcriptional, Functional, and Mechanistic Comparisons of Stem Cell-Derived Hepatocytes, HepaRG Cells, and Three-Dimensional Human Hepatocyte Spheroids as Predictive In Vitro Systems for DrugInduced Liver Injury. Drug Metabolism and Disposition. 2017 Apr 1;45(4):41929.

8. Zeilinger K, Freyer N, Damm G, Seehofer D, Knöspel F. Cell sources for in vitro human liver cell culture models. Experimental Biology and Medicine. 2016 Sep;241(15):1684-98.

9. Bell CC, Hendriks DF, Moro SM, Ellis E, Walsh J, Renblom A, Puigvert LF, Dankers AC, Jacobs F, Snoeys J, SisonYoung RL. Characterization of primary human hepatocyte spheroids as a model system for drug-induced liver injury, liver function and disease. Scientific reports. 2016 May 4;6:25187.

10.Bonn B, Svanberg P, Janefeldt A, Hultman I, Grime K. Determination of human hepatocyte intrinsic clearance for slowly metabolized compounds: comparison of a primary hepatocyte/stromal cell co-culture with plated primary hepatocytes and HepaRG. Drug Metabolism and Disposition. 2016 Apr 1;44(4):527-33.

11.Ramachandran SD, Schirmer K, Münst B, Heinz S, Ghafoory S, Wölfl S, SimonKeller K, Marx A, Øie CI, Ebert MP, Walles $\mathrm{H}$. In vitro generation of functional liver organoid-like structures using adult human cells. PloS one. 2015 Oct 21;10(10):e0139345.

\section{How to cite this article:}

Heydari Z, Vosough M. New Platforms For Drug Screening And Toxicology: Necessity Or Need?. Mod Med Lab J. 2019; 2 (1) :107-109 